\title{
A Lean Innovation Model To Help Organizations Leverage Innovation For Economic Value: A Proposal
}

\author{
Terry Frederick, Lockheed Martin, USA \\ Than Lam, Lockheed Martin, USA \\ Vicki Martin, Drexel University College of Medicine, USA
}

\begin{abstract}
This paper introduces a Lean Innovation Model for transforming an organization into one that leverages innovation for economic value. The model intends to address two main questions: 1) what are the best innovation transformation approaches for an organization to leverage innovation and 2) how can an organization effectively unleash its untapped innovation capability to increase economic value? How the model works, its constructs, and how it can affordably be implemented will be described. Relationships between the conceptual model and the requisite culture, process, and infrastructure needed for an organization to produce economic value from innovation will be explored.
\end{abstract}

Keywords: Lean Innovation Model; Innovation System; Affordability

\section{INTRODUCTION}

( $\mathrm{n}$ times of economic uncertainty, austerity and focus on affordability, an organization's need for effective and efficient innovation is a necessity for growth and competiveness. For most operating businesses, it is "an unnatural act" because the uncertainty is so high, the time horizon too long, and the investment too large, given the risks (Bessant, \& Tidd, 2004, p. 4). It is clear that innovation is a major driver of organizational success (Ahearne, Frambach, Moenaert, \& Schillewaert, 2005). Investing significant capital to develop and implement an innovation system or wait several years for culture change to provide innovation-driven economic benefit (Bessant et al., 2004) is not a luxury that organizations can afford. A lean and tailored approach for transforming an organization into an innovative culture with supporting processes and infrastructure is necessary to meet current business challenges. Internal innovation initiatives, or employing external resources to identify barriers to innovation with subsequent implementation of innovation improvement solutions, present organizations with financial risks and uncertain results.

This paper introduces a Lean Innovation Model that utilizes continuous iterations of self-assessments and incremental innovation system improvements to affordably help organizations develop an innovation system tailored to meet their current, evolving and future business needs.

\section{STATEMENT OF THE PROBLEM}

Organizations have difficulty developing innovation initiatives that effectively utilize intellectual capital for economic value, growth, and increased competiveness. Culture change and innovation system implementation attempts by organizations do not always create competitive advantage. Several well-known companies have invested poorly in innovation, resulting in disaster (Shapiro, 2011). The business landscape is riddled with examples of organizations implementing "change" programs that have not met expectations (Prince, 2007). The patents organizations generate are not applied and often do not result in economic benefit (Davis, 2008). Ultimately, the problem can best be stated in the question, "Is there a better way for an organization to efficiently transform their innovative potential into economic value?" 


\section{RESEARCH QUESTIONS}

The purpose of this paper is to introduce a Lean Innovation Model and how it should be developed for implementation. Organization self-assessments, an Innovation Transformation Action Grid (ITAG), and innovation measures comprise the model.

This research focuses on the following questions:

1. Does the Lean Innovation Model help organizations leverage innovation for economic value?

2. How do organizations unleash their untapped organizational innovation capability to increase economic value?

The hypotheses are as follows:

$\mathbf{H}_{1}$ : The lean innovation model transformation approach more effectively helps organizations leverage innovation for economic value.

$\mathbf{H}_{2}$ : Unleashing organizational intellectual capital to foster innovation leads to economic value and improved competiveness.

\section{LIMITATIONS}

Because the model has not yet been tested and validated, it may not yet be applicable to all organizations. Meanwhile, it is hoped that some organizations can take advantage of the proposed model to enhance their innovation strategies.

\section{REVIEW OF THE LITERATURE}

\section{Impact of Innovation to Organizations}

Innovation, according to Gandotra (2010), is described as the method used by organizations to create value either by developing new knowledge or by using existing knowledge in new ways. The term is often used to mean the development of new products or services, but organizations can also innovate in other ways such as through new business models, management techniques, and organizational structures. Peter Drucker once said, "Innovation is the only competitive advantage a company really has because quality improvements and price reductions can be replicated, as can technology. Therefore, if a company could have just one major capability, it should be innovation" (as cited in Heindl, 2008, p. 5). Further proof of why innovation is so important to organizations was succinctly summarized by Jeffrey Immelt, Chief Executive Officer of General Electric, who said, "The only source of profit, the only reason to invest in companies in the future is their ability to innovate" (p. 3). Innovation is a prerequisite for success and survival and has found its way to the top of the agenda at organizations around the world (Gandotra, 2010).

According to Art Fry at 3M Company, an effective and efficient innovation system should be easily understandable and taught. He stated that innovation is "where people switch to a new practice or use a new product" (as cited in Davis, 2008, p. 2). Innovation, under this definition, must be applied, it must be used, and it must be adopted in order for innovation to have occurred. "The most exhaustive definition is presented by the innovation unit of the United Kingdom department of trade and industry who see it simply as "the successful exploitation of new ideas" (Gandotra, 2010, p. 3). Without the right innovation methodology and infrastructure, organizations may be risking their future (Heindl, 2008).

For the purpose of this research, innovation will be defined as a new idea applied to initiating or improving a product, process, or service (Judge \& Robbins, 2012). There needs to be a shift from lucky innovation to predictable innovation, that is a matter of strategy and habit, where leaders embrace innovation as a core value and ensure that the right culture, methodology, and tools are in place to produce innovation as a routine part of everyone's job. How does an organization establish an innovative culture and implement an innovation system 
necessary to improve its performance? A simpler, cost-effective, practical, and systemic, approach for continuous tailoring of a transformative innovation strategy is needed.

\section{Research and Development Spending in Support of Innovation}

Organizations that rely primarily on research and development or number of patents generated to produce economic benefit may not be fully leveraging their innovative capacity. A funded Research and Development program does not ensure resulting economic benefit from innovation (Booz Allen's Annual Survey, 2011). Prince (2007) indicated there is no relationship between Research and Development spending and innovation. Booz Allen's Annual Survey of R\&D spending covers the top one thousand companies by R\&D spending. The findings are presented in Table A.

Table A: R\&D Spending to Innovation (Adapted from Booz Allen's Annual Survey, 2011)

\begin{tabular}{l} 
The major innovators across industries consistently spend less than their competitors on R\&D. They refer to these innovators \\
as "high-leverage." \\
\hline Less than $10 \%$ of companies are these "high-leverage" innovators. \\
\hline $\begin{array}{l}\text { There is no relationship between R\&D spending and financial performance as measured by profitability and other } \\
\text { conventional valuation metrics. }\end{array}$ \\
\hline $\begin{array}{l}\text { Higher spending may increase patents, but there is no relationship between the number and even the quality of patents and } \\
\text { financial performance. }\end{array}$ \\
\hline The only statistical relationship between financial metrics and innovation is gross profit as a percentage of sales.
\end{tabular}

\section{Roles of Culture in Innovation}

Without an innovative culture, it may be difficult to maximize economic benefit from innovation regardless of level of maturity of innovation, supporting processes, or infrastructure. Organizational culture enablers and inhibitors have an effect on the propensity of an organization to be innovative in new product development (Bessant $\&$ Tidd, 2004). The Department of the Army defined its innovation system as an open environment in which people develop and implement new ways of achieving individual, unit, and institutional excellence and effectiveness (as cited in Fastabend \& Simpson, 2004). Listed below are factors to consider for assessing innovative culture in an organization.

\section{Impact of Trust and Safety on Innovation}

There should be an environment of trust and safety throughout the organization from the perspective of leaders, managers, and individual contributors. The importance of trust and responsible behavior by leadership has been identified as key attributes necessary for promoting a culture of innovation (Hattori, 2004). Lack of trust or safety could lead to apathy and employee dissonance. Businesses often send conflicting messages, unaware that the dissonance they cause brings negative results (Siedman, 2007). Management may say he or she encourages input and ideas but sends undermining signals to the contrary. The mixed message can cause distrust and impede the desire of staff to bring forth innovative ideas. A firm should measure such factors and develop strategies to address deficiencies.

\section{Leadership Commitment to Innovation}

There should be credible and consistent support from executive leaders in their commitment to innovation. The executive leaders should clearly communicate the innovation strategy to the whole organization. The organization should have a Chief Innovation Officer (CIO) or person accountable for innovation.

\section{Roles of Innovation Processes and Infrastructure}

For the purpose of this research and development of the Lean Innovation Model, innovation processes are defined as the processes an organization uses to capture innovative ideas, prioritize them, and decide which ones to invest in. A firm should establish defined methods for solving business problems and identifying new opportunities. These methods could include, but are not limited to, open innovation, internal "Challenge Driven" competitions or the purchase of solutions externally (Shapiro, 2011). 
Consideration must also be given to what information technology (IT) infrastructure should be utilized to facilitate and automate established innovation capture processes. This includes collaboration tools needed for the capture and adjudication of innovative ideas. The technology skills of staff personnel or affinity to use social media and collaboration Web 2.0 tools, such as wikis, blogs, and social networking tools, should be assessed for potential impact that could impede the automation of innovation processes.

\section{Impact of Social Networks to Innovation}

An exploration of how to improve innovation in an organization would not be complete without an understanding of the impact of social networks and use of social media tools. Innovation is recognized as a major source of modern productivity growth, a central process of economic advancement, and is a social process shaped by the institutional structures in which they are embedded (Gandotra, 2010). Slayter (1996, p. 165) suggested the idea that "successful innovation is the product of a market-oriented culture coupled with entrepreneurial values." Because innovation is considered a social process, a forward-thinking organization should consider the potential transformative impact of social networks on innovation, economic value, and industry competitiveness.

"To understand how organizations use social networking and Web 2.0 tools, such as wikis, blogs, and social networking sites, to collaborate outside traditional organizational boundaries, and how process, culture and technology can solve problems and drive business model innovation," Table B depicts how different organizations are experimenting with social networking to positive effect (Cisco, 2009, p. 3).

Table B: Perceived Value of Social Networking Tools Along the Value Chain (Adapted from Cisco, 2009)

\begin{tabular}{|l|l|}
\hline \multicolumn{1}{|c|}{ Business Function } & \multicolumn{1}{c|}{ Social Networking Applications } \\
\hline Customer Relationship Management (CRM) & $\begin{array}{l}\text { - Listen to customer concerns } \\
\text { - Support/solve problems } \\
\text { - Education/spread best practices } \\
\text { - Transfer support tasks to community }\end{array}$ \\
\hline Human Resources (HR) & $\begin{array}{l}\text { - Promote company among potential employees } \\
\text { - Identify/gather information on job candidates } \\
\text { - Train employees } \\
\text { - Tap into pool of "passive" job seekers via professional social networks } \\
\text { (e.g., LinkedIn, Xing, and Video) }\end{array}$ \\
\hline Supply Relationship Management (SRM) & $\begin{array}{l}\text { - Add social layer to supply chain management } \\
\text { - Build purchasing coalitions } \\
\text { - Hire "virtual" contractors }\end{array}$ \\
\hline Product Development/Innovation & $\begin{array}{l}\text { - Solicit ideas, opinions, and feedback to incorporate them into existing } \\
\text { and/or new products and services }\end{array}$ \\
\hline Service Delivery & $\begin{array}{l}\text { - Enhance collaboration on projects and service engagements } \\
\text { - Co-create/share knowledge } \\
\text { - Collaborate on documentation }\end{array}$ \\
\hline
\end{tabular}

\section{SUMMARY OF THE LITERATURE REVIEW AND INITIAL ASSUMPTIONS}

Some emergent themes for innovation to flourish in an organization are listed in Table $\mathrm{C}$. These will serve as a starting point for development of the assessments for the Lean Innovation Model.

\section{Table C: Emergent Themes for Innovation to Flourish}

Innovative organizations have effective and efficient innovation processes and supporting IT infrastructure.

Innovative organizations are defined as those that turn the ideas and intellectual capital of their staff into economic value.

Every organization has differing levels of maturity of innovation supporting culture, infrastructure, and processes.

Mature learning organizations are indicative of the foundation for an innovative culture.

Without a mature culture of innovation, which includes trust and safety, innovation supporting processes, and infrastructure are meaningless.

Behavioral change is more effective by making simple changes first rather than implementing large programs for change.

Innovative organizations tend to have similar cultures. They encourage experimentation. They reward both success and failures. 


\section{THE LEAN INNOVATION MODEL}

\section{Model Description}

A key component of the Lean Innovation Model (Figure 1) is the assessment of an organizations innovation culture. Creating and fostering an innovative culture is paramount for an organization to leverage innovation for economic benefit and competitive advantage (Gandotra, 2010). In unison with an innovative culture, an innovation system that consists of processes and infrastructure, that act as the conduit for turning innovation into value, must be present. The Lean Innovation Model proposes a holistic approach to affordably improve an organization's innovative culture and supporting processes and infrastructure.

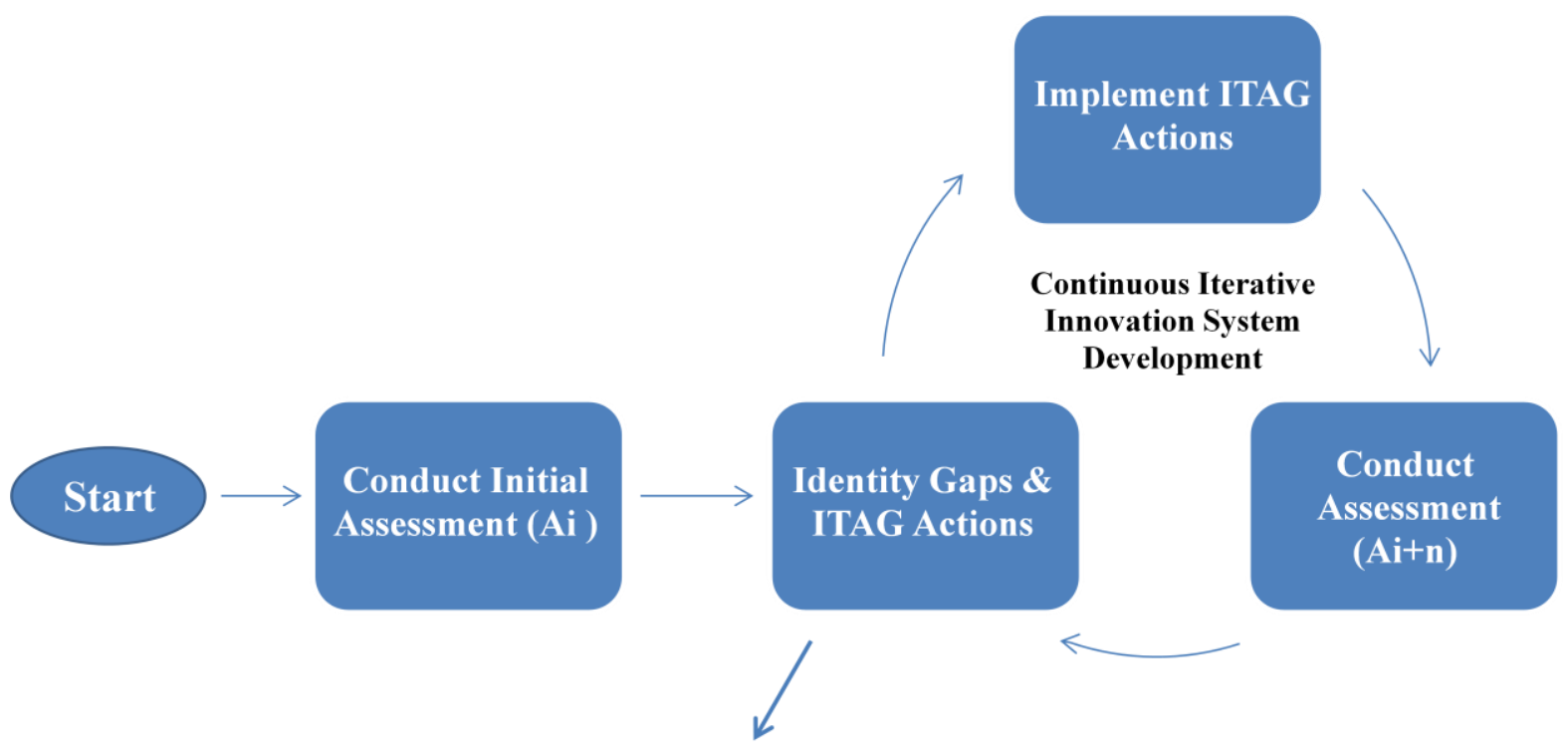

Innovation Transformation Action Grid (ITAG)

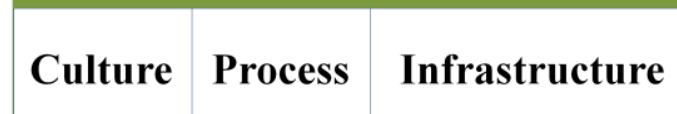

Figure 1: Lean Innovation Model

The basic construct of the Lean Innovation Model, as depicted in Figure 1, includes two main components. Assessment surveys (Appendix) are used to determine gaps or improvement areas in innovative culture, processes, and infrastructure. The Innovation Transformation Action Grid (ITAG) provides recommended improvement action steps that an organization should take based on the gaps or improvement areas identified from the assessment surveys.

\section{Development of the Model}

McIntosh and Arora (2001) suggested organizations harness their strengths and existing strategies toward innovation by fostering an optimal working environment that encourages change and allowing time for reflection to determine the impact of change. The Lean Innovation Model accommodates this premise through use of continuous assessments, making incremental change, and then allowing a time interval for "reflection" to assess the impact of those changes. Two overarching concepts from research conducted thus far have been combined to form the basis for the development of The Lean Innovation Model.

The first is the application of the "Minimum Viable Product (MVP)" development approach described by Eric Ries (2011, pp. 76-77) in the The Lean Startup, which applies a "Build-Measure-Learn Feedback Loop" to 
incrementally build a product. This approach helps to determine if a strategy is not delivering intended results so changes can be made sooner, leading to more efficient use of capital and less waste of time and money. Applied to the Lean Innovation Model (Figure 1), the expected result of the first assessment and subsequent implementation of recommended improvement changes to fill gaps is an improved innovation culture with supporting processes and infrastructure. This first instantiation of the Innovation System output from the model is the "Minimum Viable Product - MVP." Each following iteration, or "Build-Measure-Learn Feedback Loop," leads to an evolving Innovation System or "product" that is tailored to the needs of the organization. As the model shifts into gear, levels of confidence can be gained on whether investments are bearing fruit or if course corrections in strategy need to be made.

The second concept utilized for the Lean Innovation Model is the application of Persuasive Technologies (Fogg, 2009) regarding behavior change developed by B. J. Fogg of Stanford University. Since a large part of the impact on innovation in an organization is culture related, changing culture or effecting behavior change becomes a critical challenge. In developing his "The Behavior Grid: 35 Ways Behavior Can Change," Fogg asserts that targeted larger behavior change has a better chance of success if simple smaller first steps are taken toward that goal rather than trying to make big behavioral changes at once. Note that the smaller goal, which can serve as an approximation of a larger objective, is intended to be simple and more easily achievable, leading to measurable success. The process of implementing smaller changes toward the bigger goal and continuously measuring results is the same process utilized by the Lean Innovation Model.

Combining the use of lean methods to affordably build a tailored innovation system, along with the application of persuasive technologies, to effect behavior change that leads to an innovative culture are integral features of the Lean Innovation Model.

\section{Development of the Assessments Survey}

Assessment survey questions will be developed that focus on determining the state of an organization's innovative culture, processes, and infrastructure. The survey questions are intended for a sampling of employees that include individual contributors, mid-level managers, and senior executives. See Appendix A for an example of an initial assessment survey. It is anticipated that analysis of survey results will provide input to refine future assessment survey questions.

\section{Development of the Innovation Transformation Action Grid (ITAG)}

The Innovation Transformation Action Grid (ITAG), shown in Figure 1, will be developed to identify recommended improvement actions that an organization should take to address gaps or deficiencies identified in the assessment surveys relative to innovative culture, processes, and infrastructure. The concept behind development of the ITAG is similar to the theory of inventive problem-solving known as TRIZ (Altshuller, 1998 \& 1996). TRIZ is a methodology for technical problem-solving that uses 40 basic principles and has been proven to be successful. Through further research, the ITAG recommended "basic actions," similar to the basic principles of TRIZ, will be identified. The method that will be used for capturing research findings and incorporating them into the ITAG is similar to "The Literature on Characteristics of Innovative Organizations Relevant to Market and Learning Orientation Research" (Hult \& Hurley, 1998, pp. 46-47). It should be noted that the initial ITAG developed from research will continue to evolve as more data from assessments are obtained and the Lean Innovation Model is applied and measures analyzed.

\section{Usage \& Application - How the Model Works}

To apply the Lean Innovation Model (Figure 1), an initial organizational assessment (Ai) is performed to determine the existing innovative culture and innovation system (process and infrastructure) baseline. The assessment results score or rating for each of the key innovation areas (culture, process, and infrastructure) are compared with the ITAG to identify gaps or improvement areas along with prioritized steps that the organization should implement to address the gaps. The resulting Innovation System, after implementation of the recommended improvements, constitutes the organizations Minimum Viable Product (Ries, 2011) of their Innovation System. 
After a pre-determined period of time, the next assessment $(\mathrm{Ai}+\mathrm{n})$ is conducted to assess the impact of the initially implemented improvements. The resulting score or rating is once again compared with the ITAG to identify the next recommended prioritized high impact improvement steps that the organization should implement. Iterations of this process continue evolving the innovation culture, processes, and infrastructure tailored to the needs of the organization. This incremental approach offers the potential to realize benefit from targeted capital investments more quickly with expectations of improved innovation efficiency and effectiveness.

The Lean Innovation Model operation can be summarized in four basic steps:

1. Conduct Assessment

2. Identify Gaps and Actions to Take to Close Gaps Indicated by ITAG

3. Implement ITAG Recommended Improvement Actions

4. Iteratively Repeat Steps 1-3

\section{Model Testing Methods \& Measures}

A small test case of the Lean Innovation Model should be conducted to garner feedback and input. The measures used in the Lean Innovation Model are related to the assessments which identify gaps resulting in a score or rating for each of the key innovation culture, process, and infrastructure categories. Further research needs to be conducted to develop the scoring criteria of the assessment survey results and the score relationships to the ITAG. Some measures to consider include innovation accounting measures and actionable metrics proposed by Eric Ries (2009, pp. $77,143-147)$ to avoid pitfalls of "vanity measures" that lead to false conclusions.

\section{SUMMARY AND CONCLUSION}

The elements that make up a truly innovative company include: 1) a focused innovation strategy, 2) a winning overall business strategy, 3) deep customer insight, 4) great talent, and 5) the right set of capabilities to achieve successful execution (Holman, Jaruzelski, \& Loehr, 2001). The Lean Innovation Model proposed in this paper addresses this premise whereby an organization can quickly and cost-effectively assess and address its innovation culture and innovation system gaps. By conducting continuous iterations of assessments, taking improvement actions recommended by the ITAG, and measuring results, an Innovation System will evolve that is tailored to the specific needs of the organization.

Since The Lean Innovation Model is not a start from scratch approach, useful existing processes and infrastructure can be leveraged. Benefits from additional investments in innovation culture, processes, and infrastructure, along with leveraging what already exists, can be realized faster and reduce the risk of making large investments that don't meet expected results.

\section{FURTHER RESEARCH}

A case study is planned to determine the effectiveness of applying the model in a defense company located in the United States of America. Future research is needed to determine the recommended action steps contained in the Innovation Transformation Action Grid. A preliminary scan of literature on the characteristics of what constitutes an innovative culture was conducted for this paper. Additional research is recommended for supporting processes, infrastructure, and the use of social media.

\section{AUTHOR INFORMATION}

Terry Frederick has over 25 years of professional experience as a leader in engineering and information technology organizations. He is a practicing Certified Lean \& Six Sigma Black Belt (CLSSBB) with a track record of driving cost-saving process improvement initiatives. He has successfully led, mentored, and empowered teams for change and growth. In addition, he has vast experience in sales and small business ownership. Terry has received awards for program excellence, exemplary performance on Corporate Leadership Teams, and in sales and marketing. He earned his Master of Science Degree in Management from Stevens Institute of Technology, his 
Bachelor of Science in Electrical Engineering from Drexel University and his CLSSBB from Villanova University. E-mail: tfrederick57@gmail.com

Than Lam has 28 years of experience in Systems and Software Engineering and Management Information Systems. Dr. Lam serves as Lead Member Engineering Staff at the Lockheed Martin Mission Systems and Training. He served as In-Service Engineer and Program Manager at the Carderock Division of the Naval Surface Warfare Center, Assistant Professor at Temple University Fox School of Business MIS, Adjunct Professor at Green Mountain College MBA Program, and Adjunct Mathematics Instructor at Rowan University. He earned his Doctor of Business Administration from University of Phoenix, his MBA and MSEE from Penn State, and his BSEE from State University of New York-SUNY Maritime College at Fort Schuyler. E-mail: tlam123@email.phoenix.edu

Vicki Martin, MD, has over 19 years' experience as a physician leader. She is a board certified psychiatrist and has successfully led healthcare teams in diverse settings including managed care organizations, Non-profit treatment programs and Academic centers. She has served as a consultant for organizations in implementing best practice standards and coaching executives around leadership challenges, change and innovation. Dr. Martin has earned awards for promotion of best practice standards on hospital units, teaching excellence and community service. She earned her Doctorate of Medicine degree from Medical College of Georgia and will complete her MBA in Medical Management from University of Massachusetts in December, 2013.

\section{REFERENCES}

1. Ahearne, M., Frambach, R., Moenaert, R. K., \& Schillewaert, N. (2005). The adoption of information technology in the sales force. Industrial Marketing Management, 34(4), 323-336.

2. Altshuller, G. (1996). And suddenly the inventor appeared: TRIZ, the theory of inventive problem solving. Worcester, MA: Technical Innovation Center.

3. Altshuller, G. (1996). 40 principles: TRIZ keys to technical innovation. Worcester, MA: Technical Innovation Center.

4. Bessant, J., \& Tidd, J. (2004, February). Developing an organizational culture that facilitates radical innovation in a mature small to medium sized company: Emergent findings. (Working paper series). Retrieved October 24, 2013 from http://www.managing-innovation.com/case_studies/Cerulean.pdf

5. Booz \& Co (2011). Press Release. Retrieved October 25, 2013 from http://www.ipeg.eu/wpcontent/uploads/BoozCo_Press-release_Innovation_1000-_2011.pdf

6. Cisco (2009). Social media: Cultivate collaboration and innovation white paper. Retrieved October 25, 2013 from http://www.cisco.com/en/US/services/ps2961/ps2664/CiscoServicesSocial MediaWhitePaper.pdf

7. Davis, P. (2008, January). Innovation white paper. Scanlon Leadership Network. Retrieved October 25, 2013 from http://www.hope.edu/admin/frost/Assets/InnovationWhitePaper.pdf

8. Fastabend, D., \& Simpson, R. (2004). Adapt or die - The imperative for a culture of innovation in the United States Army. Retrieved October 25, 2013 from http://www.ausa.org/publications/armymagazine/ archive/2004/2/Documents/Fastabend_0204.pdf

9. Fogg, B. (2009). The behavior grid: 35 ways behavior can change. Persuasive Technology Lab, Stanford University. Retrieved October 25, 2013 from http://bjfogg.com/fbg_files/page7_1.pdf

10. Fogg, B. (2009). Creating persuasive technologies: An eight-step design process. Persuasive Technology Lab, Stanford University. Retrieved October 25, 2013from http://bjfogg.com/design_files/page8_1.pdf

11. Gandotra, N. (2010, November). Innovation Culture for Sustainable Competitive Advantage, 1(2).

12. Hattori, R. A., \& Lapidus, T. (2004). Collaboration, trust and innovative change. Journal of Change Management, 4, 97-104.

13. Heindl, D. J. (2008). Innovation infrastructure, systems approach to building an innovation organization White Paper. Nth Degree Software, Inc. Retrieved October 25, 2013 from http://www.innovationmanagement.se/wp-content/uploads/pdf/Innovation_Infrastructure_Heindl.pdf

14. Holman, R., Jaruzelski, B., \& Loehr, J. (2011, Winter). The global innovation 100: Why culture is key. Booz \& Company, 65. Retrieved October 25, 2013 from http://www.booz.com/media/uploads/ BoozCoGlobal-Innovation-1000-2011-Culture-Key.pdf 
15. Hult, G., \& Hurley, R. (1998). Innovation, market orientation, and organizational learning: An integration and empirical examination. Journal of Marketing, 62(3). Retrieved October 25, 2013 from http://www.jstor.org/discover/10.2307/1251742?uid=3739864\&uid=2\&uid=4\&uid=3739256\&sid=211028 15581787

16. Judge, T., \& Robbins, S. (2012). Essentials of organizational behavior (11 $1^{\text {th }}$ ed.). NJ: Prentice Hall.

17. McIntosh, M., \& Arora, B. (2001, February). Sustainability \& innovation, learning and cultural change. Corporate Citizenship Unit Warwick Business School University of Warwick. Retrieved October 25, 2013 from www.eauc.org.uk/sorted/files/innovation_report_-_sigma.pdf

18. Prince, T. E. (2007, June). Innovator financial styles and financial performance white paper. Perth Leadership Institute. Retrieved October 25, 2013 from http://www.perthleadership.org/Documents/ InnovatorFinancialStyles.pdf

19. Ries, E. (2011). The lean startup. New York: Crown Publishing Group. Retrieved October 25, 2013 from http://www.ebookdlhk.com/book/Lean-Startup-Eric-Ries.html

20. Seidman, D. (2007). How: Why how we do anything means everything. NJ: John Wiley \& Sons, Inc.

21. Shapiro, S. M. (2011). Best practices are stupid, 40 ways to out-innovate the competition. NY: Penguin Group.

22. Slayter, S. (1997). Developing a customer value-based theory of the firm. Journal of the Academy of Marketing Science, 25(Spring), 162-167. Retrieved October 25, 2013 from http://link.springer.com/article/10.1007\%2FBF02894352 


\section{APPENDIX A}

\section{Innovation Culture Survey}

\section{Identify Innovation Culture Gaps}

This survey is intended to help identify gaps in innovation culture. Questions included are relative to innovation process, infrastructure, and leadership practices for promoting an innovation culture. The survey allows you to express your opinions and provide information about your experiences anonymously; your name is not attached in any way to the responses you provide. The results will be used to help identify strengths and weaknesses and formulate recommended strategies for promoting and leveraging innovation. The survey has columns for your responses (Table A1). Please mark an " $\mathrm{X}$ " in the column next to each statement that best corresponds to your response (Table A2).

Table A1: Response Choices Descriptions

\begin{tabular}{|c|c|c|c|c|}
\hline SA & A & N & DA & SDA \\
\hline Strongly agree & Agree & Neutral & Disagree & Strongly disagree \\
\hline
\end{tabular}

Please avoid the neutral column as much as possible. Additional comments can be added at the end of each category. Table A2 contains Likert-type scale survey questions.

Table A2: Survey Questions on Innovation Culture

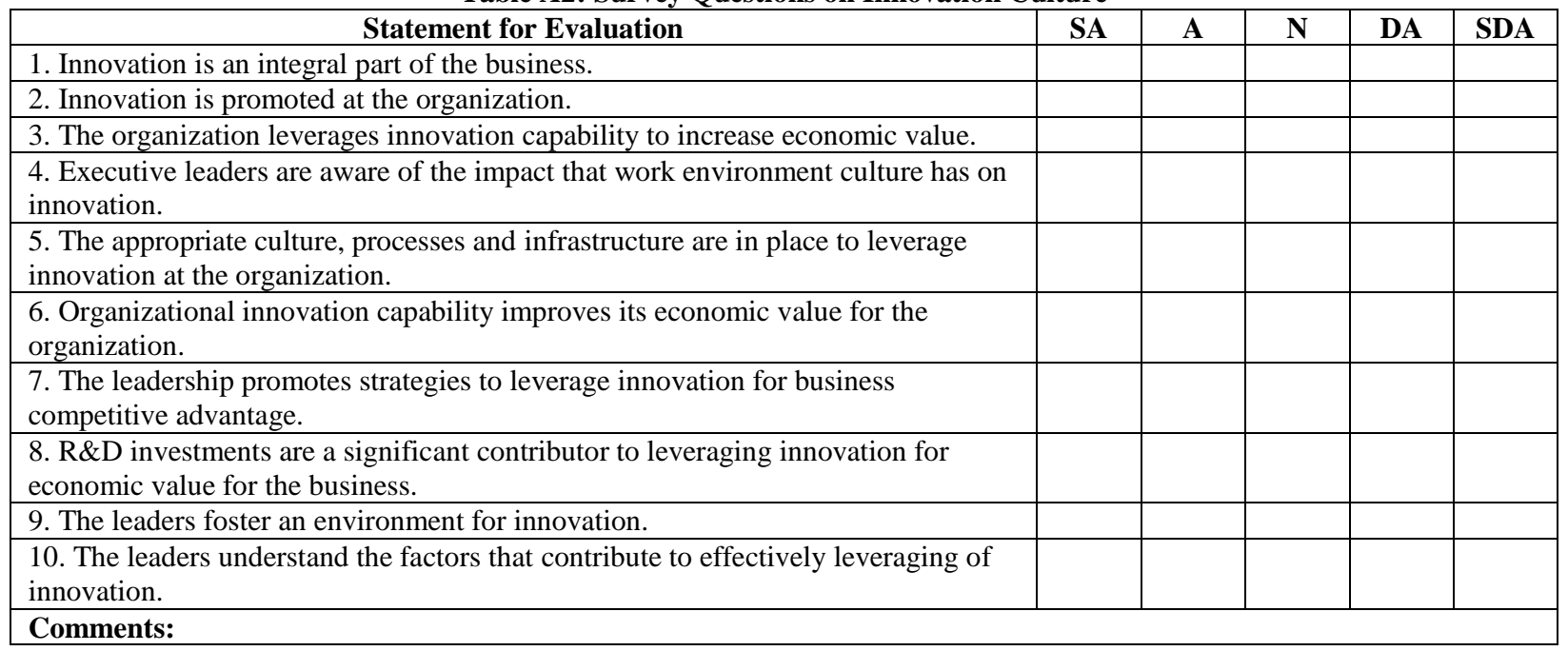

